\title{
El placer de moverse sin ver
}

\section{The pleasure of moving without seeing}

\section{Ana Carvajal}

\section{Instituto Escuela Moderna Música y Danza ${ }^{1}$}

Resumen: El presente artículo intenta descifrar la perspectiva creativa de Háptico, mi última obra de danza contemporánea. Háptico es una apuesta escénica en la que, por un lado, el sentido del tacto es el fundamento del movimiento, y por otro, la autoconciencia corporal lograda a través del método feldenkrais, ofrece un lenguaje íntimo, en un ritmo interior. Esta obra se enmarca en la línea artística que he seguido a través de mi proyecto por defecto danza, que busca poner en valor una danza democratizante, en la que los cuerpos que le dan vida no tengan que ser necesariamente virtuosos o canónicos. En Háptico esto se expresa metafóricamente, pues los performers están privados del sentido de la vista. De tal modo la obra transcurre en el riesgo de no ver y no ser visto, para que emerja el sentido del tacto en escena y en el público que empatiza con los performers.

Palabras clave: Danza Contemporánea, Método Feldenkrais, Educación Somática, Tacto, Háptico.

\begin{abstract}
This article tries to figure out the creative perspective of Háptico, my latest play of contemporary dance. Háptico is a scenic bet in which, on the one hand, the sense of touch is the central basis of movement, and, on the other, the body awareness is achieved through the Feldenkrais Method, which offers an intimate languaje, in an interior rhythm. This play is part of the artistic line that I have been following through my dance project por defecto danza, in which the bodies that give it life do not necessarily have to be virtuous or canonical. In Háptico this is expressed metaphorically, because the performers are deprived of the sense of sight. In this way, the play takes place in the risk of not seeing and not being seen, so that the sense of touch emerges on stage and in the audience that empathizes with the performers.
\end{abstract}

Keywords: Contemporary Dance, Feldenkrais Method, Somatic Education, Touch, Haptic.

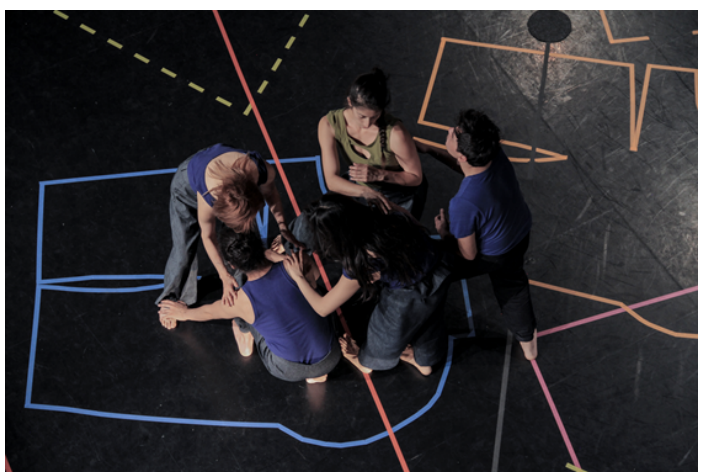

Fuente: Trabajo fotográfico Sebastián Leal

\footnotetext{
${ }^{1}$ ana.carvajal@outlook.com
} 
ANA CARVAJAL. • El placer de moverse sin ver.

\section{Problematización}

En este artículo expongo la investigación y proceso de creación de la obra Háptico, pieza de danza contemporánea que aborda el sentido del tacto desde la perspectiva somática del método feldenkrais, del cual soy practitioner certificada internacionalmente. Esta obra forma parte de una trilogía denominada "Trilogía del Pequeño Placer" en esta presento tres perspectivas respecto al tacto. Las piezas que conforman la trilogía son: Solaz, Pogo y Háptico, y en todas busco poner en valor el tacto, en cualquier conexión con nosotros mismos y los otros inmediatos. La Trilogía del Pequeño Placer tiene una perspectiva somática, entendiendo como soma el cuerpo viviente experimentado desde su interior. El gesto de tocar, el propio cuerpo o el de otro, es un gesto que está perdiendo valor epistemológico al ser suplantado por el discurso de lo touch imbricado en la tecnología.

La danza está cruzada por la idea de placer en movimiento, sin embargo pareciera que la regla para encontrar ese goce es a través del flujo continuo y una energía desbordante ¿Qué pasa cuando nos movemos poco, lento y suave? ¿Es posible encontrar una pequeña danza en nuestros huesos? Al abordar éstas preguntas surgió la problematización principal del trabajo; buscar el sentido Háptico en la danza a través de un toque suave pero concreto en nuestra estructura esquelética. El termino Háptico viene del verbo griego háptomai que significa entrar en contacto con, tocar, o agarrar. El carácter deponente del verbo (forma de voz pasiva, sentido de voz activa) refleja una de las cualidades más fundamentales de lo Háptico que corresponde a la simultaneidad de afectar y ser afectado (Porta 45).

Tocar y ser tocado, sentir es sentirse. El tacto es, sin duda, un sentido excepcional reacio a esquematizaciones, huidizo, versátil, y su peculiar relación con los otros sentidos fue lo que primero les llamó la atención a los pioneros del pensamiento Háptico. (Maurette 56)

¿Cómo relevar el sentido Háptico? El proceso de investigación y creación de Háptico fue realizado durante cuatro meses por cinco performers. Tres bailarines; Kamille Gutiérrez, Javier Muñoz y Elizabeth Tejo, un actor: Manuel González; y una persona amateur, Teresa Díaz, quién además presenta retinitis pigmentosa, enfermedad que solo le permite ver sombras en el espacio y que cada día avanza hacia la ceguera. La presencia de Teresa en los ensayos fue determinante para la toma de decisiones de la obra, pues al no ser artista escénica su situación de discapacidad se volvía más patente y muchas veces se corría el riesgo de quedar ella aparte en el trabajo exploratorio de improvisación. Debido a esto es que decidí privar a todos del sentido de la vista en la obra. Al estar todos sin ver Teresa era una más y podía perderse al igual que los otros. Entonces el cuerpo de todos cambió, todos tenían miedo de chocar, ya no era importante ser visto, si no encontrar a otro comunicarse y ese estado íntimo devalaba otro tiempo otra manera de caminar, otro cuidado con el otro y sin duda el tacto se volvía fundamental. Decidí entonces que la obra sería con los ojos cerrados, y que de esa manera tendrían que ser capaces de transitar en la estructura de la obra el movimiento pasó a ser un medio para encontrarse y ubicarse más que un fin en sí mismo.

La nueva pregunta que surgió a partir de esta decisión fue cómo armar una estructura de obra privando a los performers del sentido de la vista. La hipótesis se dirigió entonces al supuesto de que sin la vista podemos movernos desde el interior en una danza simple, que busque el placer de comunicarse con el espacio y con otros a través de un toque suave, sin la 
preocupación del cómo me muevo ni del cómo se ve el movimiento si no, con una real atención al propio cuerpo y al de los otros, desde una interioridad inexplorada escénicamente. Las estrategias para lograrlo son parte de la obra misma y es interesante como la obra termina siendo el proceso mismo puesto en escena.

Mis trabajos como coreógrafa se han caracterizado por orientar la danza hacia un territorio más concreto e íntimo. Para esto he trabajado en una danza que camina hacia lo común, lo democrático (cualquiera con un cuerpo puede bailar), y no virtuoso. Así fue mi experiencia en las obras Cocina, Medir la Distancia, Desierto de Mediodía, Creo Falso y El Salón. Estos elementos han sido centrales en mi propuesta artística, que vengo desarrollando e investigando desde el año 2003 con Cocina y que se condice con mi observación de la disciplina, efectuada tanto en Chile como en Francia y Colombia. Ello, pues creo que la danza puede tener un propósito que permita una narrativa política acerca del cuerpo y una valoración del movimiento que todas las personas desarrollan.

\section{Objetivos}

El objetivo general del proyecto fue realizar una obra de danza contemporánea que permita reflexionar acerca de la significancia e importancia del sentido del tacto humano y del contacto entre uno o más cuerpos, erigiendo un discurso fundamentado en la perspectiva somática acerca de la manera de habitar el cuerpo por parte de los seres humanos reales, más allá de los discursos artísticos subyacentes.

Objetivos Específicos:

- Profundizar en mi reflexión artística a partir de la búsqueda de las distintas diversidades del cuerpo en escena, a partir de las infinitas diferencias que presentan los cuerpos humanos y explotar el potencial artístico de todo aquello que no es canónico en la disciplina de la danza.

- Incluir la participación de aficionados a un montaje profesional de danza contemporánea, permitiendo la concurrencia en una obra de arte a personas ajenas a los códigos y lenguajes subyacentes a la danza.

- Innovar en la propuesta de obra, estableciendo una estructura capaz de ser habitada desde lo Háptico más que de lo óptico.

\section{Metodología}

El método feldenkrais está en el centro de mi propuesta creativa, pues la estructura y lenguaje de movimiento surgen de un proceso de experimentación exhaustivo de los performers en relación a las prácticas de Feldenkrais.

En mi investigación y práctica con el método feldenkrais me he dado cuenta que el tacto y el contacto son clave para desarrollar una imagen corporal mucho más acabada y concreta de sí mismo. La práctica de Integración Funcional (IF) del método es un trabajo que implica dialogar con el cuerpo de un otro a través de pequeños toques y manipulaciones de su cuerpo, de modo que, concentrándose en la estructura esquelética, se logra informar al sistema nervioso del funcionamiento del todo y sus partes, y mejorar la autoimagen somática. La 
ANA CARVAJAL. • El placer de moverse sin ver.

Autoconciencia a través del Movimiento (ATM) es la otra gran modalidad de aplicación del método, y consiste en varias series de movimientos a través de consignas que producen en los practicantes la conciencia de relación biomecánica de las partes de su cuerpo, estando estos sin ser tocados por un otro.

Los performers recibieron más de 60 lecciones de Feldenkrais de la modalidad ATM, además de cinco lecciones individuales de integración funcional. Este acercamiento dio como resultado un trabajo profundo de percepción y propiocepción (el sentido que permite comprender la posición relativa de las partes del cuerpo) inédita para cada performer. Ambas modalidades logran que las personas comprendan mejor su cuerpo (soma) y desarrollen nuevas estrategias para optimizar y hacer eficiente su uso, redundando aquello en un mayor bienestar físico-somático. Desde luego que este método tiene propiedades terapéuticas, pero esencialmente no es una terapia. Es más bien, una forma de reeducación del cuerpo a través del movimiento. El método no propone cánones ni ideales. Por el contrario, enseña que cada quien con sus fortalezas y limitaciones puede llegar a una plena organización, adecuada a su propio cuerpo en ese ahora.

Dadas las implicancias de este cambio de paradigma, es fácil imaginar cómo este método impactó en mí y en mi obra, insistiendo en la búsqueda de lo común y no virtuoso; con el fin de democratizar la danza. Los ensayos partieron siempre con una serie de ATM de feldenkrais y desde ahí se establecían las estrategias para abordar la improvisación con los ojos cerrados. Las experiencias en las ATM se trasladaron a la exploración e investigación de improvisaciones que fueron la base para establecer la estructura de la obra. Algunos conceptos trabajados fueron:

- Los límites del cuerpo: Esto se trabajó en la experimentación del abrazo, que derivó también en la caricia, el beso y el rechazo a estos gestos.

El abrazo comenzó a desarrollarse también en otras posibilidades como:

- abrazar y arrastrarse o derretirse.

- abrazar y quedarse.

- abrazar y dejar.

- abrazar otras partes del cuerpo (no el cuerpo como un total).

- ofrecerse para ser abrazado.

- enredarse en el otro.

- abrazar y trasladarse el abrazo.

- auto-abrazarse.

- El miedo a no ver

El trabajo a ciegas devela muchos miedos, es por eso que cada uno estructuró un material respecto a lo que les produce miedo y ahí surgió un material de cada uno que se puede resumir en lo siguientes temas:

- Claustrofobia.

- miedo a quedar ciego.

- miedo a las transformaciones del cuerpo. 
- miedo a caer.

\section{- La resonancia}

Feldenkrais considera nuestra estructura esquelética como una organización completamente conectada, en donde al mover una parte esta debiera resonar en el resto del cuerpo. Las vías para que resuene deben estar disponibles para ello, por eso el tono muscular que se busca debe ser el adecuado para que el movimiento viaje. Como una estructura tensengrítica en donde huesos, tendones y músculos están integrados y buscan un mismo objetivo. La tensegridad es un término que viene desde la arquitectura acuñado por Buckminster Fuller y se define como "estructuras autotensionadas compuestas por estructuras rígidas y cables, con fuerzas de tracción y compresión, que forman un todo integrado". (Da Silva 1) Así, como un puente colgante.

La resonancia fue trabajada tanto en exploraciones personales como en el trabajo del tacto, con la idea de cómo hacer resonar el toque de un otro, en otros lugares distales a donde se fue tocado.

La resonancia se investigó desde la pelvis principalmente, cómo lugar desde donde es posible rebotar y mecer produciendo resonancias en nuestro tren inferior y/o superior. En esa investigación buscamos también formas de trasladarse desde la pelvis. Descubriendo que la resonancia puede implicar repetición y ritmo.

\section{- Códigos para entender el toque del otro}

Al estar privados de la vista, la comunicación táctil debe ser muy específica para dar a entender lo que se quiere comunicar. Tuvimos que crear un lenguaje de toques para poder conversar con los otros, estos son:

\section{Tocar}

a) Ser tocado y moverse desde el punto donde recibí el toque, esto implica la adaptación del cuerpo al toque de un otro, recibirlo y sentir su resonancia.

b) Tocar el esqueleto, siguiendo los preceptos de Feldenkrais, constatamos que al tocar los huesos o lugares articulares era posible modificar más fácil al otro cuerpo. La idea de este toque es cambiar el lugar de equilibrio del otro.

c) Ir hacia el otro, buscar ser tocado, en el entrenamiento, para encontrarse más seguros al estar sin ver, realizamos un ejercicio que implica reconocer cuando está cerca la mano de otro, sin tocar. La idea es trabajar con la capacidad que tenemos de sentir los cambios de temperatura al acercarse a cualquier cuerpo. Este trabajo implica mucha concentración y no siempre resulta, sin embargo el movimiento hacia la búsqueda de un toque posible tiene una calidad concentrada enfocada muy bella. 
ANA CARVAJAL. • El placer de moverse sin ver.

d) Tocarse desde la yema de los dedos, conectarse sutilmente, las manos son un lugar con muchos receptores táctiles en nuestro organismo. Es inevitable que se hayan vuelto un lugar de exploración preponderante, sin desestimar que todo nuestro órgano piel puede ser un lugar de contacto. Obviar que las manos son principales también sería no conectar con nuestra naturaleza. Al conectar desde las yemas de los dedos transformamos ese toque en una cadena de toques que cofunde que mano realmente estoy tocando y sin embargo esas manos suaves pueden guiarme y confío, aunque sé que está igualmente ciega que yo. Es un lugar de conexión y confianza muy significativo.

e) Tocarse a sí mismos, a través de las manos y con otras superficies, como el suelo, la pared, telas, el cuerpo del otro como apoyo.

f) Agarrar y anclarse a otro, buscando apaciguar un movimiento mío o calmar el movimiento de otro.

g) Trepar a otro, encontrar lugares desde donde apoyarme para escalar o recorrer el cuerpo de otro

h) Halar a otro, dar un toque que implica un impulso de movimiento en una dirección específica, el impulso no es fuerte pues no sabemos hacia donde los estamos lanzando.

Estas maneras de moverse generaron un lenguaje de movimiento, una claridad en el espacio y sutilezas en el cómo se movían los performers. El método feldenkrais también hace énfasis respecto a la calidad del movimiento. Un movimiento eficiente tiene una calidad respecto al objetivo, por lo tanto no hay una sola calidad buena, si no que va depender de por qué nos movemos la calidad que necesitamos. En la búsqueda de un espacio seguro en donde cinco personas pudieran transitar sin ver, nos parecía importante buscar una calidad suave de movimiento, algo que no amenazara al otro, si no más bien que lo resguardara y cuidara. Esto nos llevó a tener un material de movimiento, el cual dio a frases y escenas susceptibles de ser estructuradas fijadas en un lenguaje propio que comenzaba a emerger.

Así, fueron apareciendo preguntas propiamente escénicas. Por ejemplo ¿cómo estos cuerpos se van a ubicar y desplazar en el espacio sin el sentido de la vista? ¿cómo sabrán que están en riesgo mientras se mueven? o ¿cómo pasarán de una situación a otra, si no saben lo que los otros están haciendo? Para resolver esto se incorporó al proceso de creación la artista visual Paz Carvajal y del músico Daniel Marabolí, quienes materializaron estrategias escenográficas y sonoras para guiar a los performers. En cuanto a lo escenográfico, la búsqueda fue a través de patrones y guías de costuras de las vestimentas, que dejan huellas y líneas que seguir y que conforman un mapa texturado. Respecto del sonido, se optó por guías rítmicas primitivas provenientes de los sonidos que emanan de la percusión que realizan los cuerpos en escena así la música marcó los tiempos y el ritmo de la obra. 
Finalmente, el vestuario y la iluminación de la obra fueron propuestas de la diseñadora teatral Tatiana Pimentel, quien luego de investigar diferentes texturas trabajó con la tela de jeans azul que tiene un imaginario concreto y de uso diario, pero que al mismo tiempo posee un peso y pliegue similar al del fieltro que también se usa como elemento escenográfico, pudiendo combinarse estas dos texturas confundiéndose a veces y resaltando en otras por el color. En el caso de la iluminación se buscó evocar la ceguera a través de la disposición de sombras, claroscuros y fuertes contrastes.

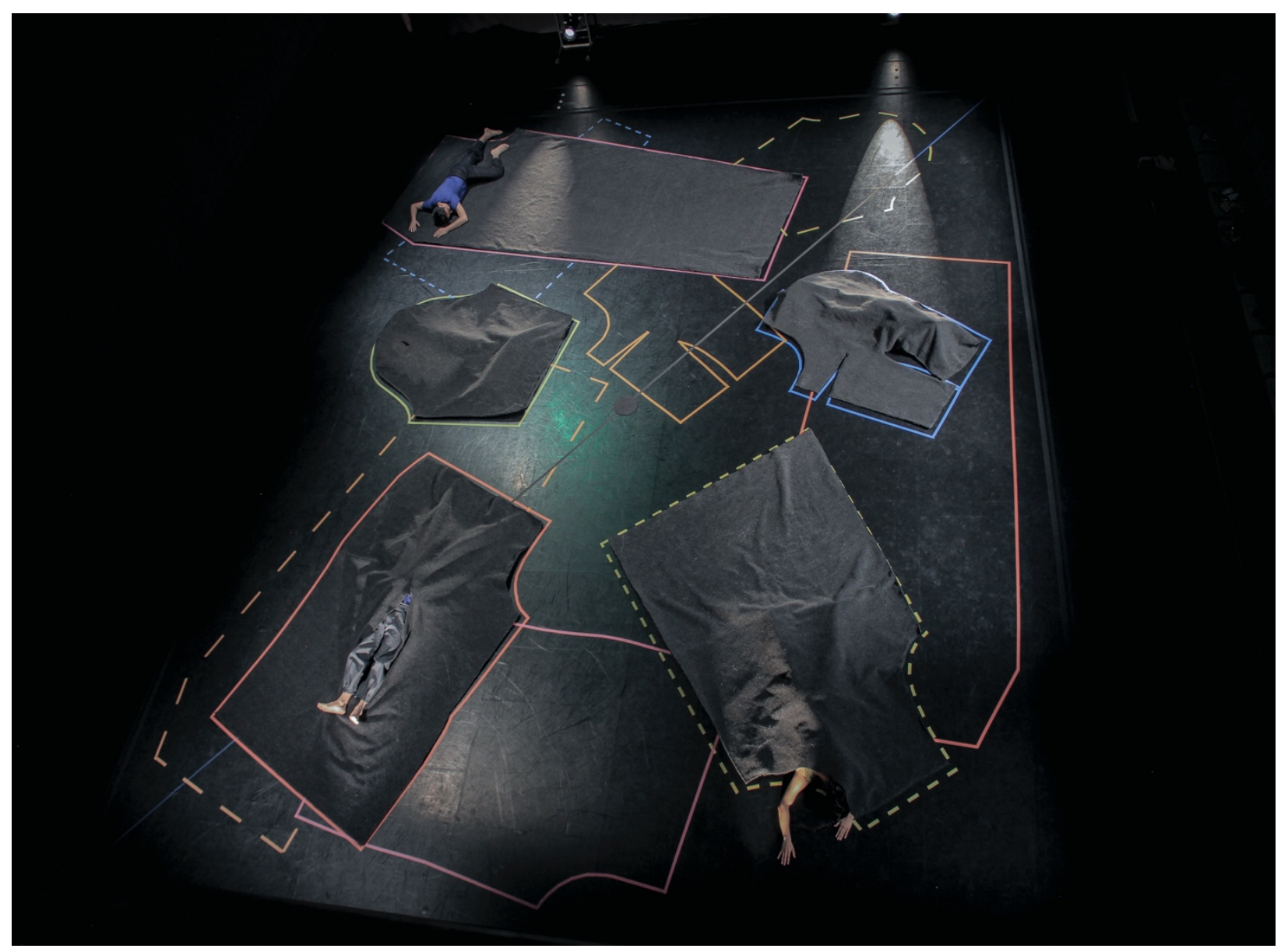

Fuente: Trabajo fotográfico Sebastián Leal

\section{Análisis de la obra}

Para analizar la obra en sí, ofrezco una evocación libre (en la que prima el uso de consignas) de cada parte de su estructura escénica. Al ser esta una obra de danza, y por tanto de una naturaleza más poética que narrativa, pienso que de este modo se transmite mejor lo que es la obra a través de sus partes. 


\section{Monstruos}

Tocar fieltros de grandes dimensiones en los cuales se puede estar dentro, tocarse a través de los fieltros y cambiar los límites, transformarme en otro que no tiene formas convencionales y que sin embargo puede comunicarse con otros y abrazar desde los distintos tipos de abrazo investigados. Es también un momento para sentir el espacio, las marcas en el piso y saber dónde se está sin mirar.

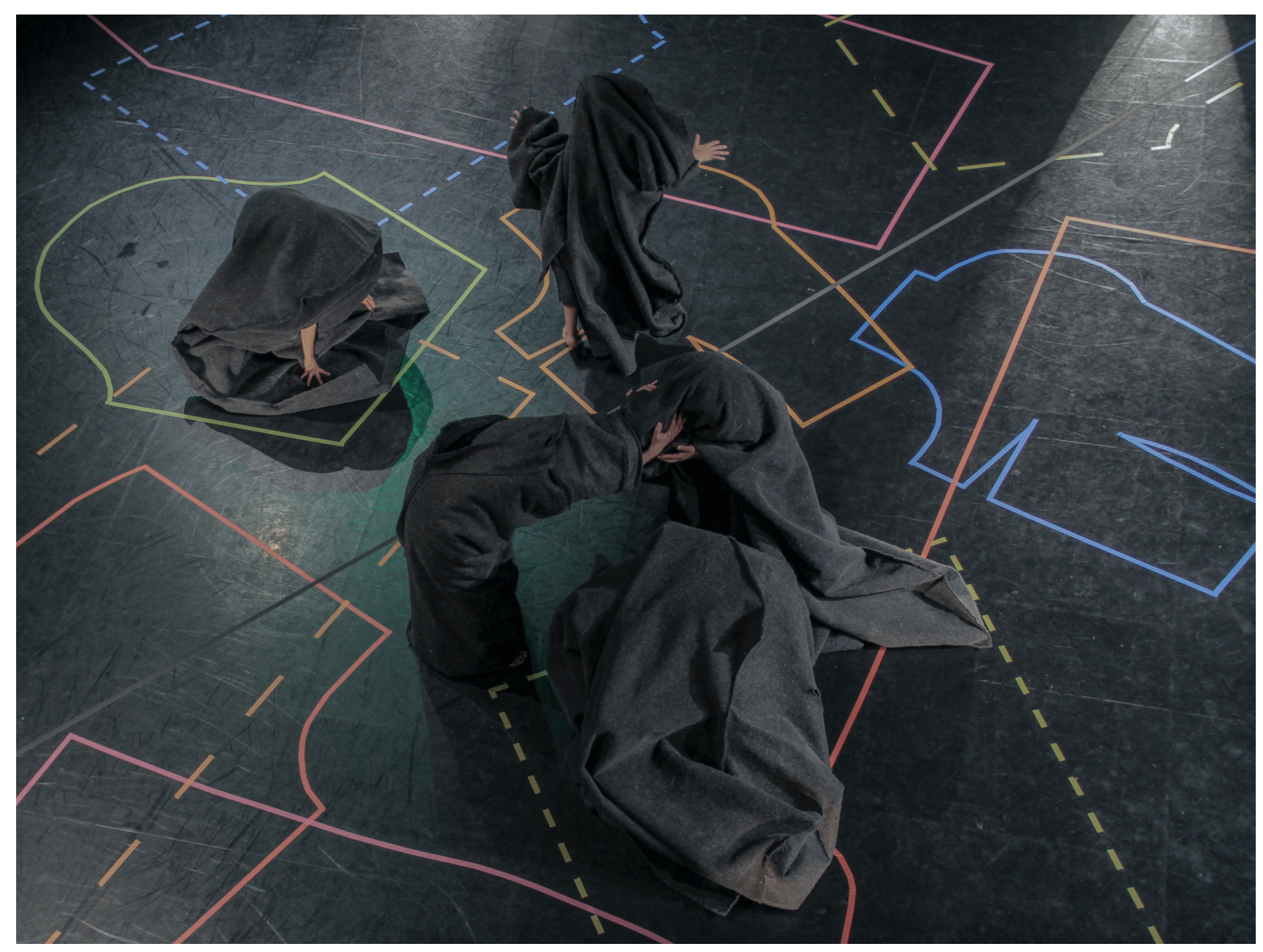

Fuente: Trabajo fotográfico Sebastián Leal

\section{Acomodos}

Tocar los fieltros, tocarse a través de los fieltros, ocuparlos como una posibilidad de estar más cómodo, descansar en ellos y en el cuerpo de los otros, en los lugares blandos, duros, rugosos de los otros y ocuparlos como apoyo.

\section{Te presiento}

No toco, pero doy calor. No me tocas pero te presiento, y juego con descubrirte. Toco para modificar tu centro y desequilibrarte. 


\section{Besar y enredar}

"El beso, es como el baile en pareja - otra forma de diálogo Háptico no verbal - la única regla de oro es sentir al otro, estar atento a sus sutilezas, a sus idiosincrasias, a sus berretines, a sus virtudes y defectos; sentir al otro y responder, o reaccionar, como corresponda en cada caso" [El Sentido Olvidado, op. Cit]. Tocar siempre es ser tocado y el beso fraterno (no romántico) tiene una dimensión háptica muy clara pues también olemos, escuchamos y saboreamos al otro. Besamos enredados, no sabemos muy bien a quién, ni dónde. Luego nos contactamos sutilmente desde las yemas de los dedos. Aquí es posible enredarse hasta caer.

\section{Volúmenes}

Amoldo y busco que el fieltro tome una forma propia y estática. Recorro sus volúmenes y dejo que cambie el espacio.

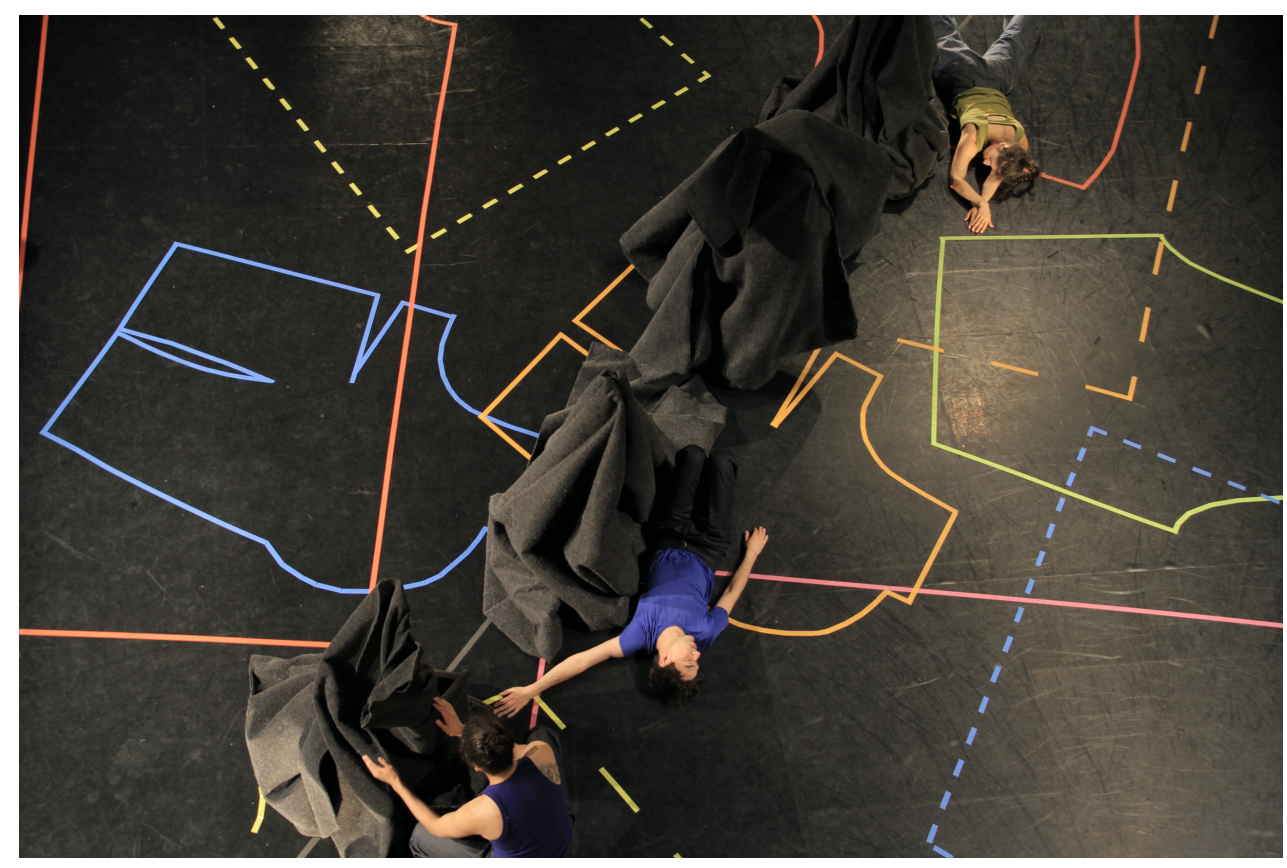

Fuente: Trabajo fotográfico Sebastián Leal

\section{Fila ciega}

Basado en un juego en donde el de atrás da las señales para dirigir a toda la fila, en el juego original el de atrás ve y puede guiar mejor el camino. Esta vez todos están ciegos y deben realmente escuchar y estar atentos a la señal del toque en el hombro para saber si caminan adelante o doblan. Aquí aparece una frase de danza más reconocible (que supone un aprendizaje visual, pero que acá no es el caso) que difícilmente sale coordinada, pese al esfuerzo de lograrlo. 


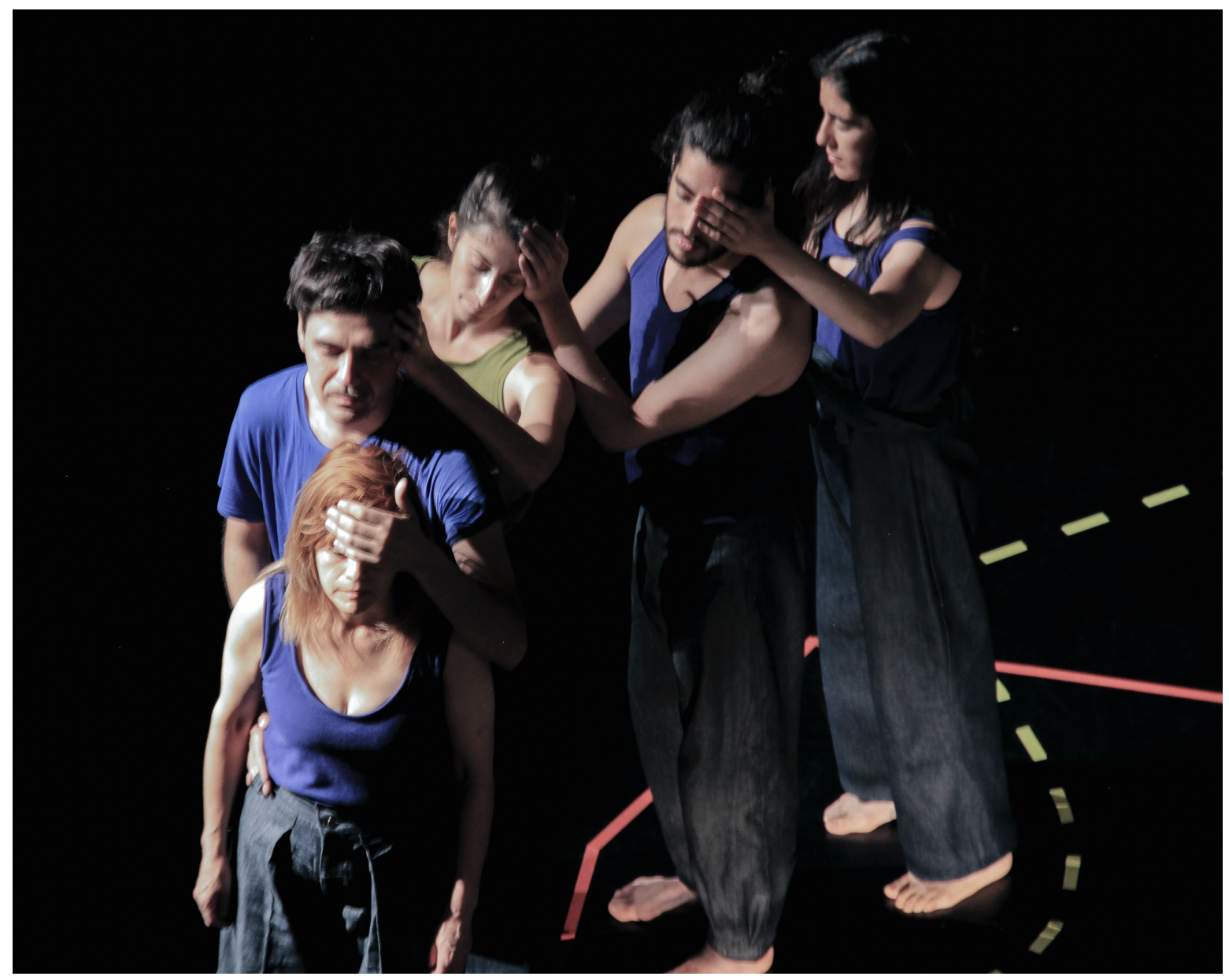

Fuente: Trabajo fotográfico Sebastián Leal

\section{Teléfono}

Existe un antiguo juego de hacer circular un mensaje al oído, si el emisor no es capaz de transmitir tal cual el mensaje original, este empieza a desvirtuarse. Trabajamos con esta idea replicada al cuerpo; el mensaje es una posición específica e inusual del cuerpo, la cual debe conocerse tocando la estructura esquelética del compañero, para luego imitarla, reproduciéndola.

\section{Toque y reacción}

Elaboramos códigos de toque que implican una respuesta automática, para dar seguridad y un ritmo distinto al movimiento. Estos toques son: dar la mano, tocar los hombros, pisar un pie, tocar la nariz, tocar la frente, tocar la espalda, tocar rodillas, dar una cachetada. 


\section{Miedos}

Esta es la fase final de la obra y aquí transitan los miedos de cada uno elaborados de diferentes maneras, comenzando con la imagen de un gran cuerpo de límites difusos y forma extraña que luego se desmiembra en otros miedos.

\section{Conclusiones}

Háptico es una obra que devela su proceso de creación en escena y esto implica que cada vez que se realiza, se experimenta nuevamente su estructura, la cual es vulnerable dada la ceguera. El hecho de tener a cinco performers trabajando sin ver lo que hacen, ni lo que los demás hacen es un hallazgo que parece simple, pues se asemeja a muchas improvisaciones en danza donde cerrar los ojos nos conecta con algo más interno o nos hace escuchar mejor la música. Sin embargo, ese placer que sin duda atraviesa a la obra, también se vuelve una tarea compleja de sostener durante 50 minutos tanto para el que observa, como para el que es observado logrando una tensión dramática inusitada.

Háptico es un trabajo profundo de cada uno de los performers en cuanto personas (más allá de artistas), pues el acento no está puesto en lograr hacer todo perfecto, si no en cómo resuelven artísticamente un dilema interno y escénico. Son frecuentes los errores o torpezas, pero todos son defectos maravillosos que revelan la preponderancia del sentido de la vista en nuestra cultura y vuelven la obra aún más háptica, pues tiene el efecto en el público de "sentir" lo que sienten los performers en escena, por la vía de la empatía. Ser público de Háptico produce una sensación similar al conectarse con los cuerpos en escena, vivenciar y casi experimentar cada gesto que hacen en el espacio y en el cuerpo de otros. La poética de la obra no responde a la forma del movimiento, sino en cómo quienes se mueven viven desde el interior el movimiento y cómo son capaces de encontrarse con el otro y ubicarse en el espacio a través del tacto, construyendo situaciones que están condicionadas por consignas y que siempre evocan la vulnerabilidad.

Este trabajo profundo se consiguió gracias al método feldenkrais, el que -sin ser una técnica de danza- es un trabajo de autoconocimiento que permite observar nuestras formas $\mathrm{y}$ volúmenes desde lo sutil y sensible del tiempo lento, contribuyendo a una certera autoimagen. En cada lección de Feldenkrais aprendemos algo nuevo de nosotros mismos, de cómo estamos emocional o síquicamente en nosotros, como nos habitamos y ese viaje se traduce en una mayor comodidad, en una relación más clara entre nuestros huesos y músculos, y pareciera que nos movemos con más facilidad. Desde la perspectiva del público, pareciera que estuviéramos asistiendo a una clase guiada de Feldenkrais, por lo tanto quien asiste también se afecta y se siente tocado sin que realmente ocurra.

Háptico sucede cada vez como una obra que se encuentra a sí misma y esa vulnerabilidad es su mayor fortaleza. Es lo que nos hace seguir y observar cada detalle de los movimientos de estas cinco personas y viajar juntos en su dimensión háptica. 
ANA CARVAJAL. • El placer de moverse sin ver.

\section{Bibliografía}

Beringer, Elizabeth. La sabiduría del cuerpo, recopilación de artículos de Moshe Feldenkrais. Buenos Aires, Argentina: Sirio, 2015. Impreso.

Da Silva, Julia Teles; Farbiarz, Jackeline Lima. El pensamiento de Buckminster Fuller en el LILD, PUC-Rio. 2016. Disponible en: <http://pdf.blucher.com.br.s3-saeast 1.amazonaws.com/designproceedings/ped2016/0170.pdf $>$. Acceso el 25 Dic 2017.

Feldenkrais, Moshe. La dificultad de ver lo obvio. Buenos Aires, Argentina: Paidos, 1992. Impreso.

Han Byung -Chul. La salvación de lo bello. Barcelona, España: Herder, 2016. Impreso.

Joly, Yvan y Eisenberg Wieder, Rose. Educación Somática, Reflexiones sobre la práctica de la conciencia del cuerpo en movimiento. México D.F, México: UNAM. 2008. Impreso.

Maurette, Pablo. El sentido olvidado, ensayos sobre el tacto. Buenos Aires, Argentina. Mardulce, 2015. Impreso.

Porta, Luis. "Narrativas sobre la enseñanza en torno a la "didáctica de autor". Las maravillas cotidianas que abren a la percepción en el aula universitaria". Revista del IICE, 37. (2015): 41-54

Recibido: 30 de Mayo de 2019

Aceptado: 16 de Octubre de 2019 